\title{
Cdx2 regulates endo-lysosomal function and epithelial cell polarity
}

\author{
Nan Gao and Klaus H. Kaestner ${ }^{1}$ \\ Department of Genetics and Institute for Diabetes, Obesity, and Metabolism, University of Pennsylvania School of Medicine, \\ Philadelphia, Pennsylvania 19104, USA
}

\begin{abstract}
In contrast to our significant understanding of signaling cascades that determine cell polarity in lower eukaryotic or immortalized cells, little is known about the transcriptional program that governs mammalian epithelial polarization in vivo. Here we show, using conditional gene ablation and three-dimensional tissue culture, that the homeobox transcription factor $\mathrm{Cdx} 2$ controls apical-basolateral polarity in mouse enterocytes and human colonic epithelial cells. $\mathrm{Cdx} 2$ regulates a comprehensive gene network involved in endo-lysosomal maturation and protein transport. In the absence of $\mathrm{Cdx} 2$, defective protein trafficking impairs apical-basal transport and induces ectopic lumen formation. These defects are partially recapitulated by suppression of key apical transport components, Rab11a and Kif3b, which are regulated by Cdx2. Furthermore, Cdx 2 deficiency affects components that control the organization of microvillus actin cytoskeleton, leading to severe microvillus atrophy. These results demonstrate that $\mathrm{Cdx} 2$ regulates epithelial cell polarity and morphogenesis through control of apical protein transport and endo-lysosomal function.
\end{abstract}

[Keywords: Cdx2; intestine; cell polarity; endosome; lysosome; apical transport]

Supplemental material is available at http://www.genesdev.org.

Received March 2, 2010; revised version accepted April 29, 2010.

Studies in lower organisms indicate that the establishment of apical-basolateral polarity requires formation of junctional landmarks and sorting of proteins to different membrane domains. An evolutionarily conserved apical junctional complex serves as a control point in initiating acquisition of polarity (Yeaman et al. 1999b). Within this polarity organization center, the Partitioning-defective (Par) complex, composed of Par3, Par6, and atypical protein kinase $\mathrm{C}(\mathrm{aPKC})$, is thought to play a pivotal role in initial apical membrane formation /Goldstein and Macara 2007), while the small Rho GTPase Cdc42 participates in the regulation of polarity (Joberty et al. 2000; Lin et al. 2000; Qiu et al. 2000). While mammalian cell culture systems have been used to explore the mechanisms of epithelial polarity formation, these models are limited due to their insufficiency of recapitulating the dynamic transcriptional program during in vivo epithelial cell development.

Abnormal intestinal epithelial cell polarity and morphology are typical features of several human pathological conditions, including intestinal tumors and microvillus diseases. Mutations in a number of genes that are involved in cell polarity regulation-including $L K B 1, P T E N$, and $A P C$-are responsible for intestinal tumors /Groden et al. 1991; Hemminki et al. 1998; Marsh et al. 1999, 2008;

${ }^{1}$ Corresponding author.

E-MAIL kaestner@mail.med.upenn.edu; FAX (215) 573-5892.

Article is online at http://www.genesdev.org/cgi/doi/10.1101/gad.1921510.
Etienne-Manneville et al. 2005; Martin-Belmonte et al. 2007; Mirouse et al. 2007; Barth et al. 2008). Mice with homozygous ablation in Rab8a, encoding a small GTPase involved in apical protein transport, demonstrate features of microvillus inclusion disease (Sato et al. 2007). While several effectors of epithelial polarity have been established, it is not clear how this essential property of the intestinal epithelium is regulated transcriptionally.

In mice, the pseudostratified posterior endoderm initiates a dramatic morphological change around embryonic day 14.5 (E14.5), polarizing into a columnar intestinal epithelial monolayer. This morphological transition coincides with the initiation of cellular differentiation. Differentiated enterocytes exhibit a striking separation of functions between their apical and basolateral domains. The apical domain faces the intestinal lumen and elaborates an impressive array of microvilli called the brush border. These sophisticated apical cellular projections dramatically increase the apical cell surface, and contain both enzymes and transporters essential for the uptake of nutrients from the intestinal lumen. The basolateral domain faces neighboring epithelial cells and the extracellular matrix, and contains intercellular junctional complexes, extracellular matrix receptors, ion channels, and solute transporters (Yeaman et al. 1999a). The molecular mechanisms by which intestinal progenitor cells elaborate the structural and functional polarity of enterocytes remains poorly understood. 
We showed recently that the caudal-type homeobox transcription factor $\mathrm{Cdx} 2$ is required for intestinal cell lineage specification in early mouse endoderm (Gao et al. 2009). At the blastocyst stage, Cdx2 controls the segregation of the inner cell mass and the trophectoderm lineages (Strumpf et al. 2005). Alteration of Cdx2 levels in mouse blastomeres, by overexpression or knockdown, influences cell division pattern, hence affecting cellular allocation and lineage specification through a mutually reinforcing relationship between cell polarity and Cdx2 (Jedrusik et al. 2008). These studies provided preliminary connections between $\mathrm{Cdx} 2$ and cell polarity regulation; however, they left open by which mechanism Cdx2 fulfills its role in controlling key aspects of the polarity machinery.

Using conditional gene ablation in the differentiated mouse intestinal epithelium, we demonstrate that $\mathrm{Cdx} 2$ deficient enterocytes exhibit abnormal endo-lysosomal trafficking, which is attributable to impaired transcriptional control of a comprehensive gene network involving endosomal transport and lysosomal biogenesis. In both mouse enterocytes and human colonic epithelial cells, the segregation of apical and basolateral plasma membrane domains and efficient protein transport to the apical plasma membrane are dependent on Cdx2. Further, we describe defective microvillus morphogenesis in $\mathrm{Cdx} 2$ deficient enterocytes that highly resembles the features of human microvillus atrophy.

\section{Results}

\section{Derivation of intestine-specific $\mathrm{Cdx} 2$ mutant mice}

To investigate whether $\mathrm{Cdx} 2$ contributes to epithelial cell polarity in the intestine, we derived intestine-specific
$C d x 2$ mutant mice $\left(C d x 2^{\operatorname{lox} P / l o x P} ;\right.$ Villin $C r e^{+}$mice, termed "mutant" for simplicity hereafter). As determined by Cdx2 immunostaining, depletion of $\mathrm{Cdx} 2$ protein from intestinal epithelial cell nuclei initiated around E15.5 in this model and reached $85 \%-95 \%$ of epithelial cells by E18.5 (Supplemental Fig. 1). PCR screening of $>300$ mouse offspring revealed that all mutant mice died on postnatal day 1 or 2 , following severe perturbations of intestinal architecture, as outlined below.

Gross examination of E16.5-E18.5 mutant gastrointestinal tracts revealed a translucent and pale appearance of the gut tube in $C d \times 2$ mutants, compared with the opaque control intestine $\left(C d x 2^{\text {loxP/loxP }}\right.$ or $\left.C d x 2^{l o x P /+}\right)($ Fig. $1 \mathrm{~A}-\mathrm{C}$; Supplemental Fig. 1). $C d x 2^{\operatorname{lox} P / \operatorname{lox} P}$; VillinCre $e^{+}$mutants developed colon and rectum, in contrast to the complete colonic atresia we observed when we deleted $C d x 2$ at the onset of gut formation (Supplemental Fig. 1; Gao et al. 2009). Concomitant with villus morphogenesis, polarization of intestinal epithelial cells initiates around E15.5 in the mouse and completes with a polarized columnar cell layer by E18.5 (Supplemental Fig. 1). Examination of mutant intestinal sections at various stages revealed shortened villi (Supplemental Fig. 1), which, in cross-section, appeared as numerous spheres of irregularly packed epithelial cells (Supplemental Fig. 2). This contrasted with the control villus epithelial cells in which the nuclei of the single-layer epithelium are orderly aligned toward the basement membrane (Supplemental Figs. 1, 2).

Examination of mutant villi by transmission electron microscopy (TEM) confirmed their highly irregular cell shape (Fig. 1E). Surprisingly, nearly all mutant cells contained a large subapical vacuole, which was absent in control cells (Fig. 1D,E). These cytoplasmic vacuoles were first detectable in a subpopulation of E15.5 mutant cells
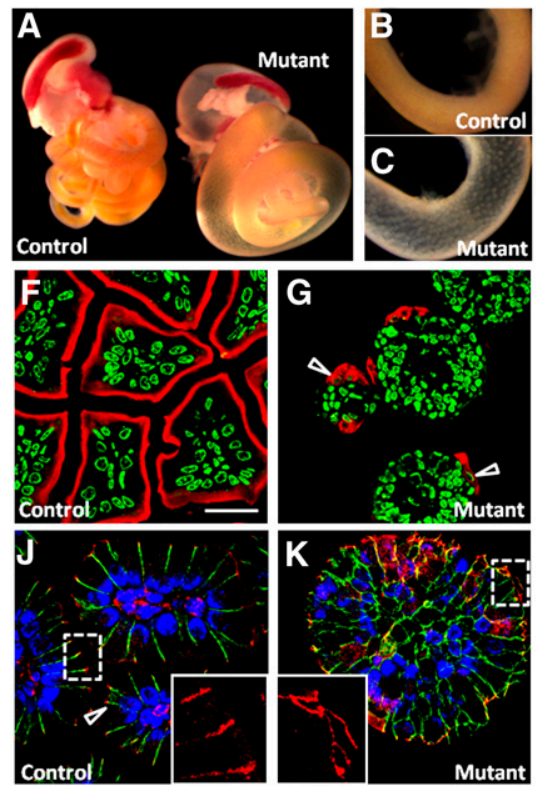
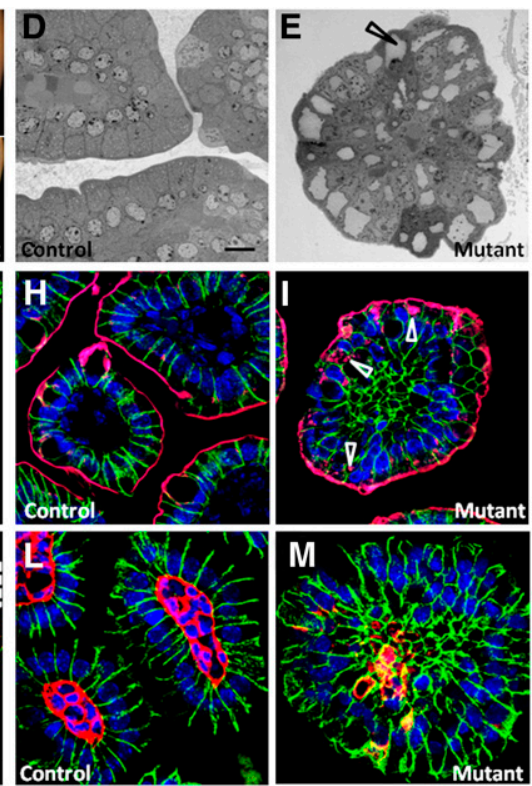

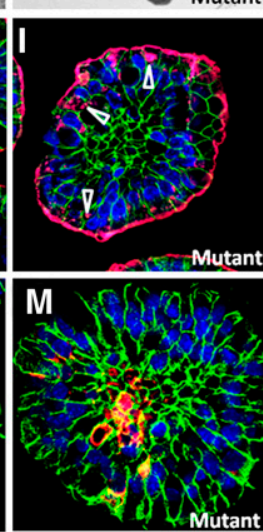

Figure 1. Intestine-specific ablation of $C d x 2$ causes altered enterocyte morphology and apical/ basolateral polarity. $(A-C)$ E18.5 gastrointestinal tracts, examined by light microscopy, revealed translucent appearance of the $C d x 2$ mutant intestinal tube. Matched control and mutant $\left(C d \times 2^{\text {loxP/loxP }} ;\right.$ VillinCre $)$ duodenal segments are shown in $B$ and $C$ at higher magnification. $(D,-E)$ TEM micrographs of E18.5 control and $C d x 2$ mutant intestinal villus cross-sections. The arrow in $E$ points to one of the enlarged vacuoles in the mutant cells. $(F, G)$ The brush border marker alkaline phosphatase was immunostained and is visualized in red. Nuclei are labeled in green. Arrows point to the abnormal distribution of alkaline phosphatase activity on the entire $C d x 2$ mutant cell membrane. $(H, I)$ Costaining of DBA lectin (red) and E-cadherin (green). Arrows point to the inclusion of lectin staining within subapical cytoplasm in mutant cells. $(J, K)$ Costaining of ZO-1 tight junction protein (red) and E-cadherin (green). The arrow points to ZO-1 localization at tight junctions in control cells. $(L, M)$ Costaining of the basement membrane marker laminin (red) and E-cadherin (green). Establishment of the basement membrane is clearly perturbed in the absence of Cdx2. Nuclei were labeled by DAPI in $H-M$. Bars: $D, E, 10 \mu \mathrm{m} ; F-M, 20 \mu \mathrm{m}$. 
by TEM (Supplemental Fig. 3); that is, shortly after Cdx2 protein has been depleted (Supplemental Fig. 1).

Despite the altered epithelial morphology, mutant enterocytes in the outermost layer of the Cdx2-deficient epithelium formed apical microvilli (Supplemental Fig. 3). Goblet cells were detected throughout the mutant intestines by Alcian blue staining (Supplemental Fig. 4). In addition, no apparent squamous differentiation was detected in the mutant intestinal epithelium. These data demonstrate that the mutant epithelial cells had committed to intestinal fates by the time that $C d \times 2$ was deleted by the VillinCre transgene, and that the observed phenotypes in the current model were not due to the cell fate conversion that occurs in early endoderm-specific Cdx2 mutants (Gao et al. 2009).

\section{Disrupted apical-basal polarity in Cdx2-deficient mouse enterocytes}

To determine if the brush borders of the mutant enterocytes express apical markers indicative of normal digestive function, we analyzed the distribution of alkaline phosphatase, an enzyme that is targeted exclusively to the apical brush border in normal enterocytes (Fig. 1F; Supplemental Fig. 4). Although some mutant cells demonstrated alkaline phosphatase activity, this was present on the entire cellular membrane, including the presumptive basolateral surfaces (Fig. 1G). "Inclusion" of alkaline phosphatase activity, one of the specific diagnostic features of the microvillus inclusion disease (Lake 1988), was confirmed by light microscopic analysis of the mutant cells (Supplemental Fig. 4). Staining for Dolichos biflorus (DBA) lectin, which is selective for glycoconjugates on the mucosal surface (Fig. $1 \mathrm{H}, \mathrm{I})$, indicated that the mucin secretory function of goblet cells was unaffected by the absence of $\mathrm{Cdx} 2$ protein. However, inclusion of this marker at subapical cytoplasmic regions was also detected in mutant cells (Fig. 1I), while in control cells the staining was located almost exclusively to the luminal surface (Fig. 1H). Most strikingly, E-cadherin, a basolateral membrane marker that is excluded from the apical surface in normal intestinal epithelial cells, demonstrated ectopic localization to the entire cellular membrane in the mutant cells (Fig. 1H-M; Supplemental Fig. 2), confirming polarity defects in the Cdx2-deficient intestine.

To examine the integrity of the tight junctions that divide the apical and basolateral domains, we stained intestinal epithelia simultaneously for the tight junction protein ZO-1 and E-cadherin. In control cells, ZO-1 was localized at the apical end of the E-cadherin-expressing domain (Fig. 1J). In contrast, mutant cells demonstrated an expanded ZO-1-positive membrane domain, with a reticular staining pattern that comprised the outer layers of the multilayered epithelium (Fig. 1K). This colocalization of ZO-1 and E-cadherin in $C d \times 2$ mutants was confirmed by staining of tangential villus sections (Supplemental Fig. 5). Perturbed apical/basolateral partitioning was further supported by laminin staining, which illustrated an impaired assembly of the basement membrane in mutant epithelia (Fig. 1L,M). These data demonstrate that Cdx2 is required for the establishment and/or maintenance of cellular polarity in enterocytes.

\section{Cdx2-deficient enterocytes display microvillus atrophy}

To obtain a three-dimensional (3D) view of the luminal epithelial architecture of the Cdx2-deficient epithelium, we performed scanning electron microscopic (SEM) analysis on control and mutant intestines. Control intestinal epithelial cells showed a smooth luminal surface, distinct intercellular junctions, and densely packed microvilli (Fig. 2A,C; Supplemental Fig. 6). In contrast, mutant luminal surfaces appeared uneven, lacked clear demarcations between epithelial cells, and demonstrated dramatically enlarged and disorganized microvilli (Fig. 2B,D; Supplemental Fig. 6).

Quantification of microvillus dimensions revealed that the mutant microvilli were not only shorter $(46 \%$ of control, $P=1.05^{-21}$, but also were larger in diameter $\left(157 \%\right.$ of control, $\left.P=2.73^{-18}\right)$ (Fig. 2E,J; Supplemental Fig. 6). Vertical microvillus sections showed a lack of distinct core actin filament bundles (Fig. $2 \mathrm{~K}$ ), which were clearly present and attached to the subapical cytoplasm in control microvilli (Fig. 2F). Transverse sections through the apical cytoplasmic region showed absence of a distinct terminal web in Cdx2-deficient cells (Fig. 2L,M), as compared with the presence of numerous bundled actin microfilaments in control sections (Fig. 2G,H). Transverse sections through control microvilli demonstrated the presence of 20-30 actin filaments bundled at the microvillus core (Fig. 2I), while the actin filaments in mutant microvilli were spread throughout the microvillus crosssection (Fig. 2N). As a result, a clear cytoplasmic space was visible between the bundled actin filaments and the plasma membrane in control microvilli, while this region was absent from mutant microvilli (Fig. 2I,N). In addition, the density of microvilli on the apical surface was much lower in mutant cells than in controls (Fig. 2I,N). Despite these morphologic alterations, mutant cells did form tubular invaginations, known as canaliculi, between microvilli (Fig. 2L).

To gain insight into the molecular basis of the abnormal microvillus structure in $C d \times 2$-defcient intestinal epithelia, we performed Western blots for a number of key components involved in actin cytoskeleton organization. Surprisingly, the levels of actin itself and those of two bundling proteins that contribute to the microvillar core-villin and plastin-were not significantly changed in mutant intestinal epithelia (Fig. 2O). No apparent difference was observed for the terminal web protein spectrin and two critical myosins, Myo6 and Myo5b, which are involved in protein recycling and vesicle trafficking (Fig. 2P; Ameen and Apodaca 2007; Millman et al. 2008). However, the levels of the brush border myosin Myola were decreased by $\sim 50 \%$ in the mutant intestine $(P=0.024)$ (Supplemental Fig. 7), while the expression of its light chain, calmodulin, and its homolog, Myole, were unchanged (Fig. 2Q).

Ezrin, radixin, and moesin (the "ERM" proteins) function as linkers between the plasma membrane and the 

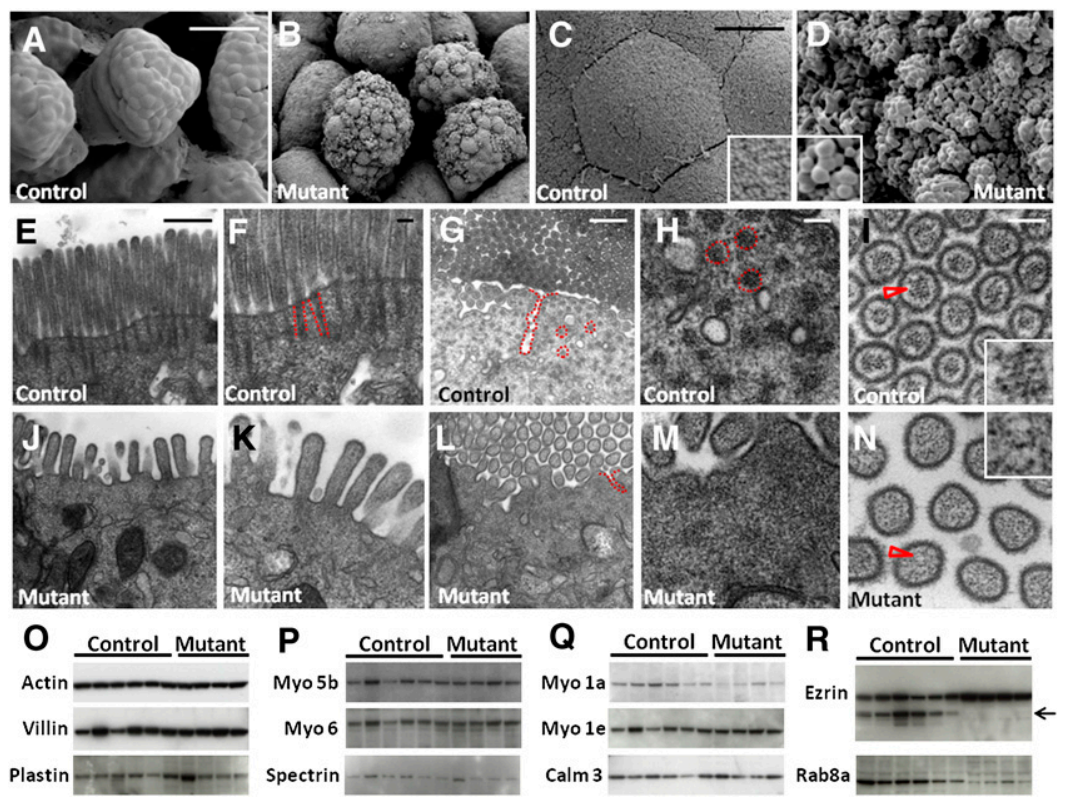

Figure 2. Intestine-specific $\mathrm{Cdx} 2$ deficiency results in abnormal microvillus morphogenesis. $(A-D)$ SEM demonstrates "uneven" luminal cell surface and abnormal microvillus morphology in $C d \times 2$ mutant intestines. $(E, F, J, K)$ Vertical TEM sections show shortened microvilli in $C d \times 2$ mutant cells (shown in J). In addition, the normal bundled appearance of actin filaments at the microvillar core is absent in $C d \times 2$-deficient cells $(K)$, as compared with control cells $(E, F)$. Red dotted lines mark two bundled actin filaments extending from the microvilli into the apical cytoplasm. $(G, H, L, M)$ Transverse TEM sections show that actin microfilament bundles, indicated by red broken circles in control cellular terminal web in $G$ and $H$, are missing in mutant cells (shown in $L, M$ ). Mutant cells develop canaliculi marked by red dotted lines in $L .(I, N)$ Transverse TEM section of microvilli reveals absence of bundled actin filaments at the microvillar core in $C d x 2$ mutant cells (shown in N). Red arrows point to the core actin filaments. $(O-R)$ Western blots for protein components of the microvillar core actin filaments $(O)$, the cytoplasmic terminal web $(P)$, the bridging proteins between the actin filaments and the plasma membrane, and Rab8a, the small GTPase regulating apical protein transport $(Q, R)$. Arrow in $R$ points to the smaller products, which were present only in control intestines, recognized by Ezrin antibody. Bars: $A, B, G, L, 50 \mu \mathrm{m} ; C, D, 5 \mu \mathrm{m} ; E, I, 500 \mathrm{~nm} ; F, H, I, K, M, N, 100 \mathrm{~nm}$.

actin cytoskeleton (Yonemura and Tsukita 1999). In the developing intestine, Ezrin is the only ERM protein present, and it organizes the apical terminal web region (Saotome et al. 2004). In contrast to the decreased Myola levels, we found that the expression levels of the $81-\mathrm{kDa}$ full-length Ezrin were increased 1.3-fold in mutant intestines compared with controls $(P=0.009)$ (Supplemental Fig. 7). Interestingly, a smaller putative Ezrin isoform or splicing variant of $62 \mathrm{kDa}$ was completely missing from mutant intestinal samples (Fig. 2R, arrow). Analysis of the mouse Ezrin locus revealed that the gene encodes two transcripts, the longer one encoding a protein of 586 residues corresponding to the $81-\mathrm{kDa}$ isoform, and the shorter one encoding an ORF of 429 amino acids, corresponding to a product of $62 \mathrm{kDa}$. Our data suggest that $\mathrm{Cdx} 2$ may differentially regulate the expression of these two transcripts.

In addition, we detected an $\sim 30 \%$ reduction in Rab8a, a small GTPase involved in apical protein translocation (Sato et al. 2007), in the mutant intestine $(P=0.01)$ (Fig. $2 \mathrm{R})$. While these data show clear molecular defects in apical protein trafficking and terminal web assembly, individual changes in Myola, Ezrin, and Rab8a are not likely responsible for the cellular phenotype of the Cdx2deficient enterocytes, since no dramatic cell polarity alteration was observed in either Ezrin ${ }^{-1-}$ (Saotome et al. 2004), Myo1a $a^{-1-}$ (Tyska et al. 2005), or Rab8a $a^{-/-}$(Sato et al. 2007) mouse intestines.

\section{CDX2 is required for the apical-basal polarity in human colonic epithelial cells}

To determine whether human CDX2 plays a conserved role in regulating intestinal epithelial cell polarity, we employed a 3D epithelial cell cyst formation assay. We achieved efficient suppression of CDX2 protein levels in Caco-2 cells using CDX2-specific lentiviral shRNA particles (Fig. 3A). When Caco-2 cells were cultured in a 3D matrigel environment (Jaffe et al. 2008), control cells treated with nontargeting shRNA lentiviral particles developed cyst-like structures within a few days (Fig. 3B), with $92 \%$ of the cysts demonstrating a fluid-filled central lumen within $5 \mathrm{~d}$ of culture (Fig. 3B; Supplemental Fig. 8). In contrast, $\sim 89 \%$ of CDX2 knockdown cells failed to elaborate a central lumen, but instead developed into epithelial balls with multiple small cavities (Fig. 3C). This difference became noticeable as early as $48 \mathrm{~h}$ (Fig. $3 \mathrm{D}, \mathrm{E})$. Multiple intracystic spaces were evident in older CDX2 knockdown cysts by the accumulation of F-actin (Fig. 3F,G). Apical-basolateral identity was clearly CDX2dependent, as indicated by staining for additional basolateral markers including E-cadherin (Fig. 3D-G), CTNNB1 (Fig. 3H,I), and $\mathrm{Na}^{+} / \mathrm{K}^{+}$-ATPase (Fig. 3J,K). The difference between the 3D structures of CDX2-containing or CDX2-deficient cysts was confirmed by Z-stack imaging through the entire cyst (Supplemental Movies 1,2).

\section{CDX2 deficiency affects Par complex localization and activity}

Interestingly, in these 3D cultured CDX2 knockdown Caco-2 cysts, PRKCZ, a component of the PAR polarity complex, was localized to multiple small lumens (Fig. $3 \mathrm{M})$, while in control cysts, PRKCZ was concentrated at the apical membrane facing the central lumen (Fig. 3L). Using an in vitro protein kinase $\mathrm{C}$ assay, we detected a $26 \%$ reduction of PRKCZ activity in CDX2 knockdown cells as compared with control cells (Fig. 3N). This 


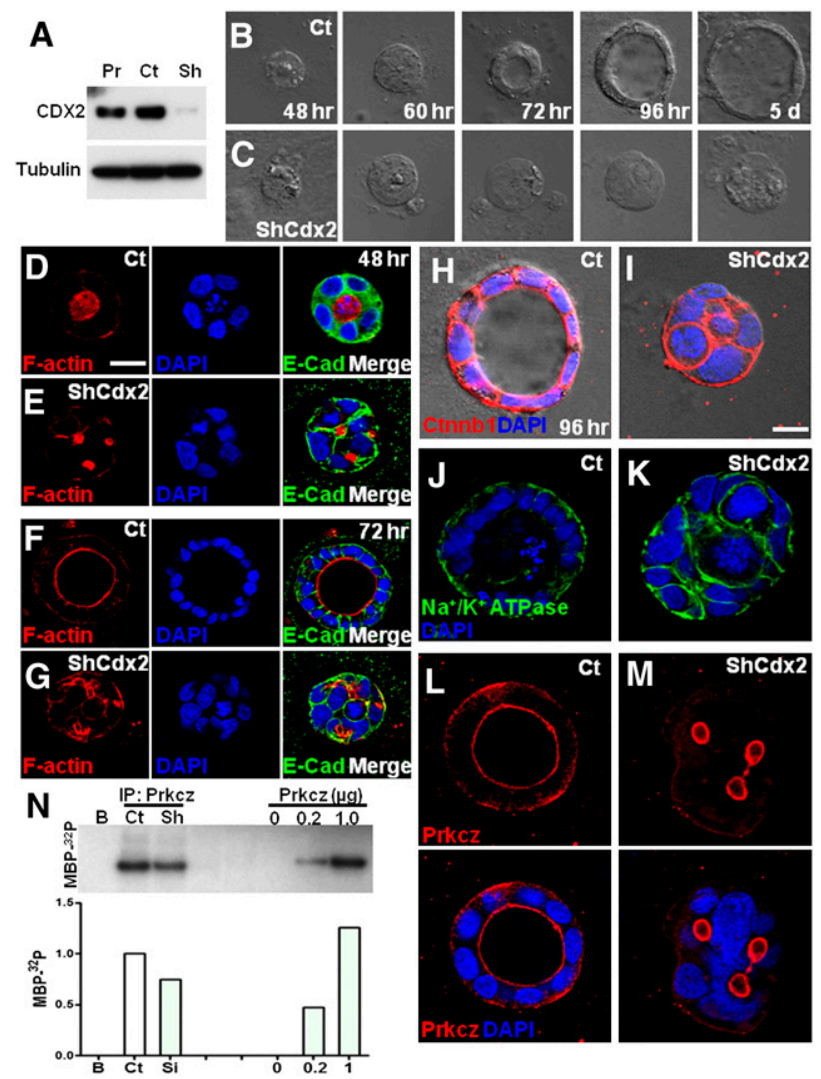

Figure 3. $\mathrm{CDX} 2$ is required for apical-basal polarity in human Caco-2 cells. (A) Western blot for CDX2 demonstrates efficient knockdown of CDX2 expression in lentiviral shCDX2 transduced Caco- 2 cells (Sh), compared with parental cells $(\mathrm{Pr})$ and nontargeting lentiviral particle-treated control cells $(\mathrm{Ct})$, at first passage after viral transduction. $(B, C)$ Control Caco- 2 cells form cysts in 3D culture within $72 \mathrm{~h}$, demonstrating a central lumen, while CDX2 knockdown cells fail to form a primary lumen even after 5 -d culture. $(D-G)$ Cysts were stained for F-actin (red), E-cadherin (green), and DAPI (blue) at various time points. Note that CDX2 knockdown cells elaborate multiple small lumens at $48 \mathrm{~h}(E)$, but fail to promote a central lumen $(G) .(H, I)$ Cysts were stained for basolateral marker CTNNB1 ( $\beta$-catenin) (red). $(J, K)$ Cysts were stained for a basal transporter, $\mathrm{Na}^{+} / \mathrm{K}^{+}$-ATPase (green). $(L, M)$ Control and CDX2-deficient Caco-2 cysts were stained for PRKCZ in red. Nuclei were labeled by DAPI in blue. $(N)$ In vitro protein kinase $\mathrm{C}$ assay demonstrates a reduction of PRKCZ kinase activity in CDX2-deficient cells by $25.6 \%$. Bars, $20 \mu \mathrm{m}$.

reduction was likely due to altered protein localization, as total PRKCZ levels were equivalent between control and CDX2 knockdown cells (Supplemental Fig. 9). Although the altered PRKCZ localization in CDX2 knockdown cysts was reminiscent of the CDC42 knockdown Caco-2 cysts (Jaffe et al. 2008), total CDC42 and activated CDC42 levels were unchanged in CDX2 knockdown Caco-2 cells (Supplemental Fig. 9).

A recent study using early mouse blastomeres has linked $C d \times 2$ to aPKC (Jedrusik et al. 2008). To determine whether the protein levels of the Par polarity complex changed in $C d \times 2$ mutant intestines, we performed West- ern blot analysis using tissue lysates of E18.5 control and $C d \times 2$ mutant intestines. Surprisingly, most of these protein components, except for Cdc42, showed elevated levels in mutant intestine, with Par-3, Par-6A, and Par6B demonstrating increases of more than twofold (Fig. 4A; Supplemental Fig. 10). Next, we analyzed two additional Par polarity proteins, Lkb1 (Par-4) and Mark2 (Par-1), and found both proteins significantly increased in the mutant intestine (Fig. 4A), while the levels of activated Cdc42 remained constant (Fig. 4B). These data suggest that the effect of $C d x 2$ deficiency on the assembly of the apical Par polarity complex may not be due to direct transcriptional regulation by $\mathrm{Cdx} 2$.

Analysis of Prkcz localization in $C d \times 2$ mutant intestinal epithelia revealed an ectopic distribution of this protein to the nonapical membrane domains (Fig. 4D,F), where they colocalized with E-cadherin. In contrast, Prkcz was detected predominantly at the apical membrane domain in control intestinal cells (Fig. 4C,E). This impaired Prkcz distribution is consistent with the mislocalization of this molecule in CDX2 knockdown cysts (Fig. 3M).

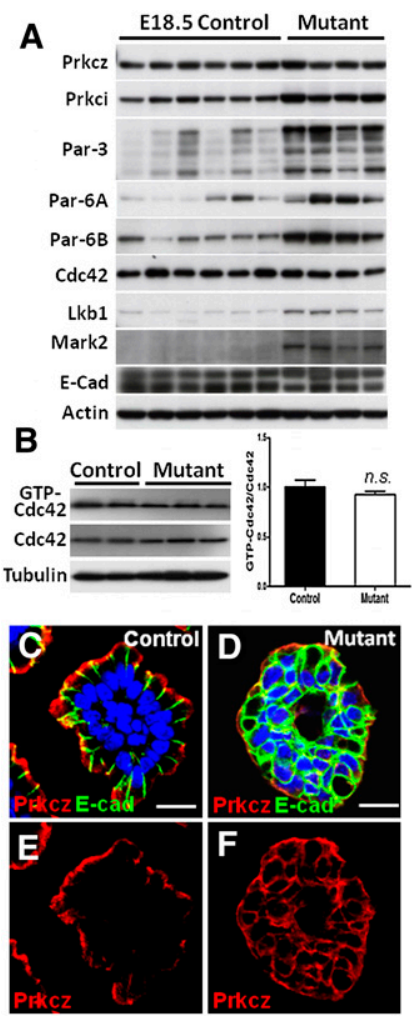

Figure 4. Cdx2 deficiency leads to elevated expression of Par components, and mislocalization of Prkcz. (A) Intestine-specific Cdx2 deficiency leads to increased levels of several of Par polarity proteins, but not $\mathrm{Cdc} 42$. (B) Total or activated Cdc42 levels are not changed in $C d \times 2$ mutant intestines. $(C-F)$ Immunofluorescent staining of Prkcz (red) and E-cadherin (green) demonstrates nonapical localization of Prkcz localization in mutant cells. Nuclei were labeled by DAPI in $C$ and $D$. Bars: $12.87 \mu \mathrm{m}$. 


\section{Cdx2 controls a gene network involving endo-lysosomal function}

Based on the severity of the overall enterocyte phenotype and the significant perturbation of molecular markers presented above, we hypothesized that $\mathrm{Cdx} 2$ deficiency likely affected a more fundamental cellular function, which in turn would affect the assembly of the Par polarity complex. In order to identify this function, we performed microarray analysis using four pairs of E18.5 control and $C d \times 2$ mutant small intestinal mRNA samples. Analysis of the expression profile using the NIH DAVID Functional Annotation Tool (Dennis et al. 2003) revealed "vacuole and lysosome," as the top-ranked category with the highest enrichment score $(P=3.8 \mathrm{E}-27)$ (Fig. 5A). This category contains 82 genes encompassing almost every aspect of endo-lysosomal structure and function (Fig. 5B; Supplemental Table 1). Among these genes, the transcription factor EB (Tfeb), a recently reported master regulator of lysosomal biogenesis and function (Sardiello et al. 2009), was significantly decreased in the $C d \times 2$ mutant intestine. Western blot analysis detected a significant reduction of Tfeb even in E16.5 Cdx2 mutant intestine (Fig. 5C), when initial Cdx2 deletion was evident. As Cdx2 deletion became complete at E18.5 (Supplemental Fig. 1), Tfeb levels were reduced further. These data suggest that reduced Tfeb expression is an early event affecting the development of $C d \times 2$ mutant cells.

Notably, the majority of the Cdx2-dependent lysosomal membrane proteins and proton pumps are also expressed in early or late endosomes. Indeed, $18.7 \%$ of the down-regulated genes that are classified as being involved in cellular organelle or protein transport contain major components of the protein trafficking machinery (Fig. 5A; Supplemental Table 2). These include key components of apical protein transport (Rab8a, Rab11a, Kif3b, Rab17, Rip11, Sec15A, Optn, Htt, Ehd1, etc.), and the retromer endosomal complex (Vps26, Vps29, and Snxs), which plays a role in apical transcytosis.

Next, we first performed Western blot analysis to investigate to what extent the microarray findings correlate with protein levels. Although the transcript levels of most lysosomal genes were decreased as described above, protein levels of Lamp1 (lysosomal-associated membrane protein 1) were elevated in the $\mathrm{Cdx} 2$ mutant intestine (Fig. 5D; Supplemental Fig. 11). In addition, glycosylated Lamp2 levels were increased in mutant cells (Fig. 5D), indicating its slower rate of Golgi transit in the mutant cells (Nabi and Dennis 1998). Furthermore, in mutant tissues, we detected the inactive $52-\mathrm{kDa}$ proenzyme form of Cathepsin D (Ctsd), a ubiquitous lysosomal protease that was completely activated and processed into its 34$\mathrm{kDa}$ and $14-\mathrm{kDa}$ subunits in control intestines (Fig. 5D). These data demonstrate that $\mathrm{Cdx} 2$ deficieny affects lysosomal protein transport, processing, assembly, and degradation. Since lysosomal defects-e.g., a deficiency of lysosomal enzymes and/or altered lysosomal $\mathrm{pH}-$ can result in the accumulation of undegraded proteins and other macromolecules, the failure of lysosomal degradation activity likely explains the formation of the
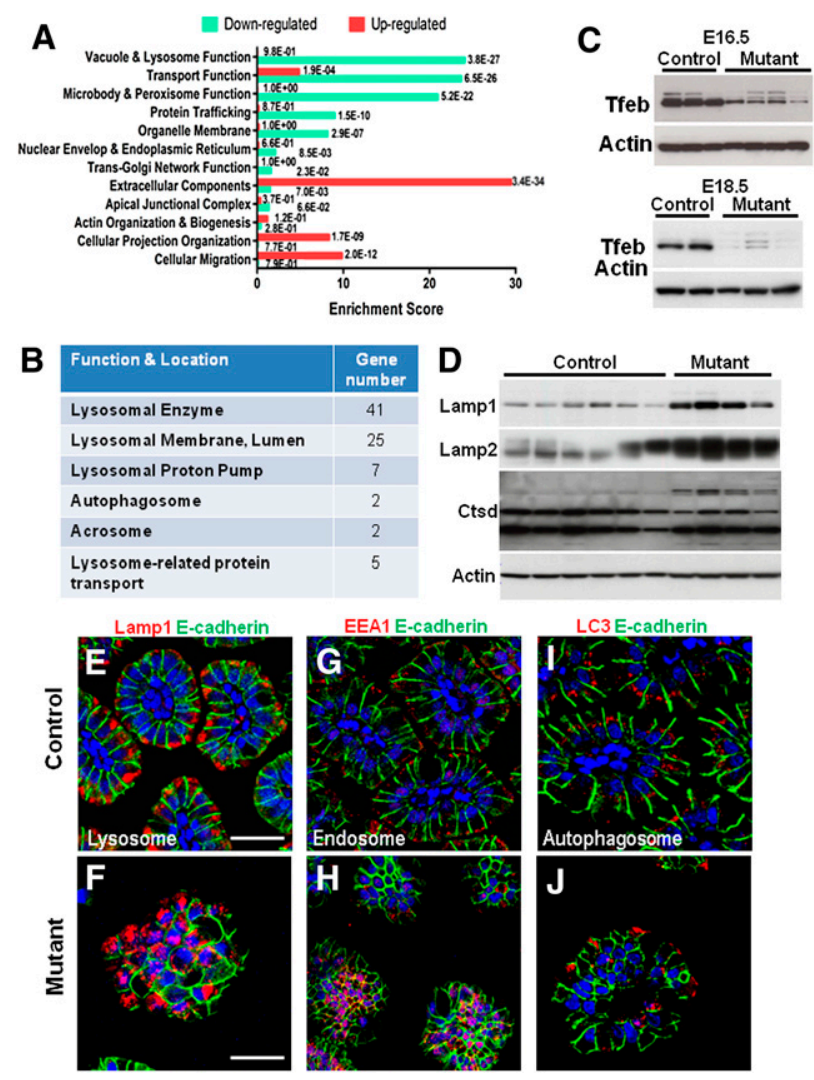

Figure 5. $C d \times 2$ deficiency impairs endo-lysosomal maturation and function in enterocytes. (A) Using high-stringency gene classification, functional annotation of the expression profile of normal and mutant E18.5 intestines reveals that the gene category of "vacuole and lysosome" has the highest enrichment score among the down-regulated genes, followed by "transport function," "microbody and peroxisome," "protein trafficking," and "organelle membrane." The statistical significance of the enrichment of each category is indicated as the $P$-value on the side of the corresponding bar. $(B)$ Eighty-two endo-lysosomal genes involving various aspects of endosomal and lysosomal biology are reduced in mutant intestines. $(C)$ Tfeb, a transcription factor identified by microarray analysis, is initially reduced in the E16.5, and is decreased further in E18.5 Cdx2 mutant intestines. (D) Western blots for lysosomal markers (Lamp1, Lamp2, and Ctsd) using control and $C d \times 2$ mutant intestinal lysates. $(E, F)$ Lamp1 staining (red) in control and $C d \times 2$ mutant enterocytes. $(G, H)$ Immunofluerescent staining for the early endosome marker EEA1 (red). $(I, J)$ Immunofluorescent staining for the autophagosome marker LC3 (red). Basolateral plasma membranes were labeled with E-cadherin (green). Nuclei were labeled by DAPI. Bars: $E-I, 12 \mu \mathrm{m}$.

large vacuoles we observed in $C d x 2$-deficient enterocytes (Fig. 1E).

Next, we investigated the onset of the lysosomal defect in $C d x 2$ mutant mice. Immunofluoresence staining for Lamp1 in E15.5 mutant intestine, when Cdx2 ablation first becomes apparent, showed partially normal and partially aggregated Lamp1 protein localization (Supplemental Fig. 12). A few days later, the aberrant localization of Lampl became more pronounced (Fig. 5F), while lysosomes in control mice were orderly situated near the 
apical plasma membrane (Fig. 5E). However, this localization defect was not specific to lysosomes, since the cellular distribution of endosomes (Fig. 5G,H) and autophagosomes (Fig. 5I,J), both organelles that communicate with lysosomes, was perturbed as well. These data provide additional evidence for defective endo-lysosomal trafficking and function in $\mathrm{Cd} \times 2$-deficient enterocytes.

\section{Inhibition of endo-lysosomal maturation perturbs cell polarity}

Next, we addressed the question whether inhibition of endo-lysosomal maturation or function is sufficient to alter apical-basal cell polarity. To this end, we employed various inhibitors of endo-lysosomal function in our 3D epithelial cyst assay. Both bafilomycin A1 (Baf.A1) (Fig. 6B), a highly specific inhibitor of the vacuolar type $\mathrm{H}^{+}$ATPase located at the endosomal/lysosomal membrane, and chloroquine (CHL) (Fig. 6C), a weak base that inhibits lysosomal hydrolases by reducing the acidification of the endosomal/lysosomal compartments, caused severe apical-basal polarity defects after a 3-d incubation. Treatment of wild-type Caco-2 cells with these inhibitors elicited a dose-dependent accumulation of Lamp1 protein levels, suggesting a response to the blockage of lysosomal maturation (Fig. 6H). This is consistent with the observation of increased Lamp1 and Lamp2 protein expression in the $C d \times 2$ mutant intestine described above (Fig. 5D). In contrast, levels of Prkcz and Par-3 were only slightly affected by the endo-lysosomal inhibitors (Fig. $6 \mathrm{H})$, again suggesting that the effect on the Par complex is secondary. Only few cysts survived after prolonged CHL treatment; therefore, we employed $50 \mathrm{nM}$ Baf.Al for subsequent experiments. Not surprisingly, Baf.A1 treatment resulted in the malformation of the apical lumen in a large majority of cysts, as indicated by Prkcz staining (Fig. $6 \mathrm{D}, \mathrm{E}$ ), and in perturbation of endosome distribution, as illustrated by the endosomal marker EEA1 (Fig. 6F,G). Intriguingly, before the apical lumen appears in control cysts, early endosomes are already clustered to the apical domain where the central lumen will emerge (Fig. 6I). In contrast, this early clustering of endosomes was impaired in Cdx2 knockdown cysts (Fig. 6J); however, accumulation of these endosomes around ectopic lumens was found in older knockdown cysts (Fig. 6K). These data suggest that the impaired apical-basal polarity of Cdx2deficient cells is attributable to defective endo-lysosomal function; however, they cannot differentiate apical transport from lysosomal functions due to the nonspecificity of these inhibitors.

\section{Inhibition of apical transport partially recapitulates Cdx2-deficient polarity defect}

Having established that inhibition of endo-lysosomal function elicits cell polarity defects resembling those seen after Cdx2 suppression, we wanted to evaluate which of the Cdx2 targets in the endo-lysomomal trafficking system might mediate the observed cell polarity defects. As multiple factors of the apical transport machinery were affected in the $C d \times 2$ mutant intestine
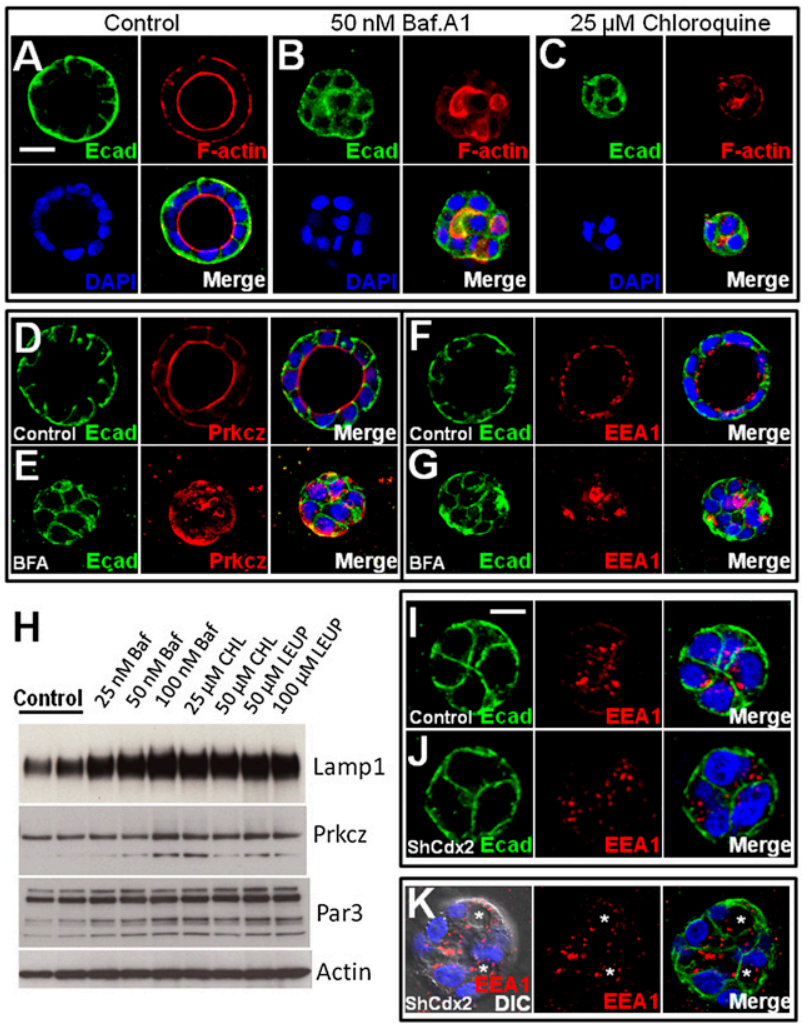

Figure 6. Blockage of endo-lysosomal maturation perturbs apical-basal cell polarity. $(A-C)$ Caco-2 $3 \mathrm{D}$ cyst formation assays were performed with 3-d incubation with normal growth medium (control), or medium containing $50 \mathrm{nM}$ Baf.A1 or $25 \mu \mathrm{M}$ CHL. F-actin and E-cadherin were stained in red and green, respectively. $(D, E)$ Control and Baf.A1-treated cysts were stained for Prkcz (red) and E-cadherin (green). $(F, G)$ Control and Baf.A1treated cysts were stained for EEA1 (red) and E-cadherin (green). $(H)$ Western blots for Lamp1, Prkcz, and Par3 using lysates from Caco- 2 cells treated with inhibitors overnight at indicated concentrations. Leupeptin serves as a nonspecific protease inhibitor. $\beta$-Actin serves as a loading control. $(I, I)$ Early cysts from control and CDX2 knockdown cells were stained for EEA1 (red) and E-cadherin (green). Note that control endosomes are clustered apically into the center where the prospective lumen will emerge. (K) Three-day-old CDX2 knockdown cysts were stained with EEA1 (red) and E-cadherin (green). Note that the knockdown cells are able to accumulate endosomes around several ectopic lumens (asterisks). Bars: $A-G, K, 20 \mu \mathrm{m} ; I, J, 9 \mu \mathrm{m}$.

(Supplemental Table 2), we chose to examine the effects of suppressing two factors not directly associated with lysosomal function: Rab11a, a recycling endosomal Rab GTPase (Weisz and Rodriguez-Boulan 2009), and Kif3b, a microtubule-dependent motor protein that complexes with Rip11 and Rab11a (Schonteich et al. 2008). The transcriptional levels of Rab1la and Kif3b were decreased by 2.2-fold and 1.7-fold, respectively, in the Cdx2-deficient intestine compared with control tissue. We performed 3D cyst formation assays using Caco-2 cells infected with validated lentiviral shRNA particles specifically targeting these genes (Supplemental Fig. 13). As depicted by Prkcz staining, $65 \%$ of the Rab11a knockdown cysts (Fig. 7A,E) 

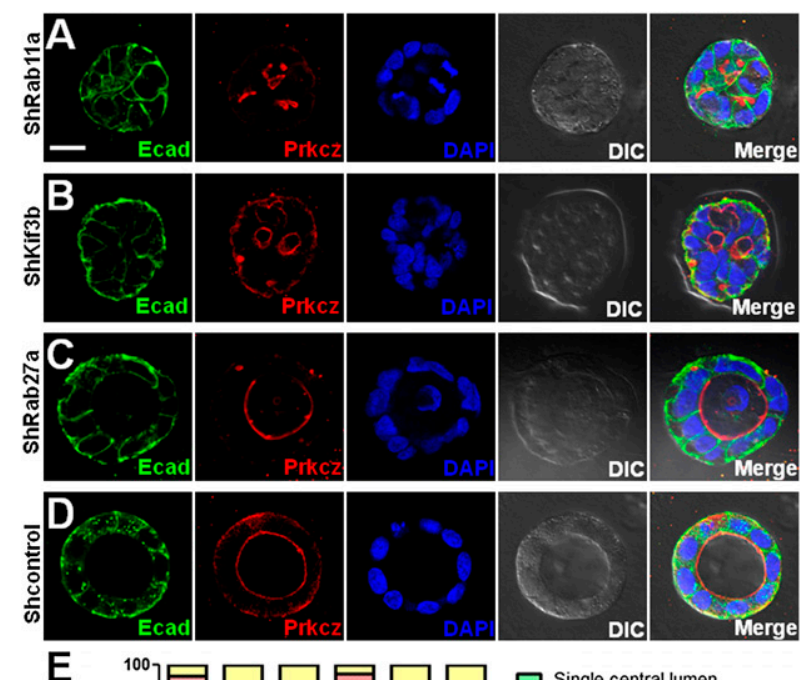

$\mathbf{E}$

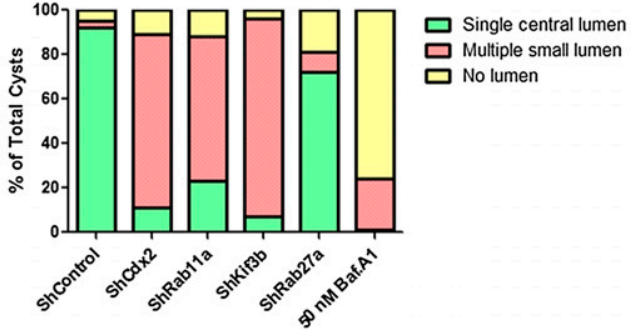

Figure 7. Suppression of apical transport proteins recapitulates CDX2 knockdown polarity defects. $(A-D)$ Caco-2 cysts derived from RAB11A, KIF3B, and RAB27A knockdown cells, as well as control cells infected with nontargeting shRNA viral particles, were stained for PRKCZ (red) and E-cadherin (green). Bar, $20 \mu \mathrm{m}$. (E) Percentage of cysts with single central lumen, no lumen, or multiple lumens were quantified. Data represent multiple independent experiments.

and $89 \%$ of the Kif3b knockdown cysts (Fig. 7B,E) demonstrated multiple small lumens, resembling the phenotype resulting from $\mathrm{Cdx} 2$ suppression (Fig. 7E). However, suppression of Rab27a, a Rab GTPase involved in exocytosis of lysosome-related organelles and secretory granules (Izumi 2007), had little effect on lumen formation in the cyst assay (Fig. 7C). Taken together, these data suggest that the role of $\mathrm{Cdx} 2$ in apical protein transport is mediated, at least in part, through its targets in endolysosomal maturation and function.

\section{Discussion}

\section{Cdx2 and endo-lysosomal function}

Abnormal endosomal/lysosomal trafficking and unusual ultrastructural endo-lysosomal features have been reported in both mouse (Sato et al. 2007) and human microvillus inclusion diseases (Morroni et al. 2006). The transcriptional control of various components of the intestinal lysosomal and ubiquitin-dependent degradative pathways have been only partially explored in several in vitro culture models (Zhang et al. 1995). Lysosomal delivery of the brush border hydrolases sucrase-isomaltase and dipeptidylpeptidase IV has been described in cultured intestinal epithelial cells (Matter et al. 1990). Agents that block the transport of brush border enzymes trap them in Lamp1-positive lysosomal bodies (Baricault et al. 1993). Interestingly, a recent study established that lysosomal genes always exhibit a coordinated transcriptional behavior and are regulated by the transcription factor Tfeb (Sardiello et al. 2009), a gene that was deactivated in the $C d x 2$ mutant intestine. These results are consistent with our finding of comprehensive down-regulation of endolysosomal gene expression in $C d \times 2$ mutant intestines.

Recent studies suggested that newly synthesized apical polypeptides, such as sucrose-isomaltase and lactasephlorizin hydrolase, sequentially traverse through Rab4-, Rab8-, and Rab11-positive endosomes to the apical surface in polarized Madin-Darby canine kidney cells (CrammBehrens et al. 2008). The expression of a number of apical transport components-including Rab8a, Rab11a, and $\mathrm{Kif} 3 \mathrm{~b}$ - is reduced in Cdx2-deficient intestines. Suppression of either RAB11A or KIF3B in epithelial cysts partially reproduced the defects of $\mathrm{Cdx} 2$ knockdown cysts, suggesting that these proteins are responsible, at least in part, for the trafficking defect in Cdx-2-deficient epithelial cells. Although the expression of individual $\mathrm{Cdx} 2$ targets is not reduced to zero in the $\mathrm{Cdx} 2$-deficient intestine, we propose that a comprehensive reduction of multiple components of this network impairs its function. In support of this notion, patients with microvillus inclusion disease caused by a RAB8A mutation exhibited only partial reduction in RAB8A protein levels (Sato et al. 2007). Our study provides in vivo evidence of transcriptional regulation of key apical transport components by Cdx2 during enterocyte development.

Although our in vitro Caco-2 cyst experiments suggest that apical transport, not lysosomal, deficiency is the primary cause of defective lumen formation and apicalbasal polarization, abnormal post-translational processing of several lysosomal proteins was evident in $C d x 2$ mutant intestines, and was likely secondary to organelle failure. Remarkably, 41 genes encoding lysosomal enzymes were significantly affected at the transcriptional level, providing a molecular explanation for the defective lysosomal degradation machinery, as well as the appearance of unusual inclusion vacuoles in $\mathrm{Cdx} 2$-deficient enterocytes. This inefficient degradation of cellular materials thus explains the increase in protein levels of a number of membrane proteins in $C d x 2$ mutant cells.

\section{Cdx2, cell polarity, and microvillus morphogenesis}

Cell polarity and microvillus morphogenesis in enterocytes are two closely related morphological events, both requiring correct apical-basolateral protein sorting and vesicle trafficking. However, establishment of apical basolateral polarity in the intestinal epithelium seems to be a prerequisite step for the elaboration of the apical microvillus brush border. Rab8a-deficient intestinal cells fail to deliver essential proteins to the apical membrane domain, causing microvillus inclusion in mutant enterocytes (Sato et al. 2007). In contrast, cell polarity is maintained in the intestinal epithelia of Myo1a (Tyska 
et al. 2005) or Ezrin (Saotome et al. 2004) knockout mice, which show limited defects at the level of microvilli or the terminal web. Both Rab8a and Myola expression is reduced in the $C d x$ 2-deficient intestine at both the mRNA and protein levels, and $C d \times 2$-deficient enterocytes share a number of features with these previously established models. For instance, apical peptidases and transporters are abnormally trapped in multiple enlarged lysosomes in the small intestine of Rab8-deficient mice, resulting in defective localization and degradation of these proteins (Sato et al. 2007). In Cdx2-deficient enterocytes, we found spreading of Prkcz expression into nonapical plasma membrane domains. The shortening of microvilli is also a common phenotype between Rab8a and $C d \times 2$ mutant enterocytes. These in vivo data further supported the idea that $\mathrm{Cdx} 2$ is upstream of the apical transport machinery that encompasses Rab8a.

Interestingly, some of the ultrastructural features, including the abnormal microvillus brush border organization, in $C d \times 2$-deficient enterocytes are very similar to those observed in Myo1a mutant enterocytes (Tyska et al. 2005). However, instead of finding loss of multiple cytoskeletal and membrane components from the brush border, as demonstrated by Myola mutant enterocytes (Tyska et al. 2005), the expression of the majority of brush border components-including the core actin cytoskeletal, terminal web, actin-bundling, and actin-plasma-bridging components-was maintained in Cdx2-deficient enterocytes. Thus, the remaining Myola in Cdx2-deficient enterocytes is sufficient for partial maintenance of microvillar structures.

Although the number of microvillar actin filaments appears not to be reduced in $C d \times 2$-deficent enterocytes, as indicated by F-actin levels, their bundling and attachment to the apical terminal web are clearly affected. Ezrin is a linker protein connecting actin cytoskeleton and membrane protein, and plays a critical role in organizing the terminal web region (Saotome et al. 2004). We speculate that the loss of a putative smaller form of Ezrin may partially contribute to the affected actin organization at this region, an issue that warrants future functional studies.

\section{Cdx2 and the Par polarity complex}

Using mouse intestinal epithelia and human colonic epithelial Caco-2 cells, we performed a systemic analysis to explore the mechanistic connection between $\mathrm{Cdx} 2$ and the key apical polarity complex Par3-Par6-aPKC-Cdc42. In both models, $\mathrm{Cdx} 2$ does not contribute directly to the transcriptional activation of these component proteins. Due to the apparent alteration of Prkcz localization in Cdx2-deficient cells, we propose that the modestly reduced Prkcz kinase activity is the result of its changed subcellular localization. One interesting observation in CDX2 knockdown Caco-2 cells is the localization of PRKCZ to multiple small lumens that are formed ectopically between cells. CDX2-deficient cells are still able to accumulate actin filaments, as well as early endosomes, to these mispositioned membrane domains, suggesting an attempt to elaborate a lumen. We propose that the effect of CDX2 defiency on the PAR complex is an indirect consequence of defective endo-lysosomal trafficking and/or function, and that, despite its abnormal localization, the Par polarity machinery maintains part of its activity to promote multiple ectopic lumen formation in CDX2-deficient cells. In summary, we established CDX2 as an essential upstream genetic regulator that controls endosomal transport and lysosomal maturation to facilitate apical-basal polarity formation and microvillus morphogenesis in intestinal enterocytes.

\section{Materials and methods}

Mice

The $C d \times 2^{l o x P}$ mice and VillinCre mice have been described previously (Madison et al. 2002; Gao et al. 2009). Control and mutant embryos used for experiments were derived from plug matings between $C d \times 2^{\text {loxP/+ }}$ VillinCre $e^{+}$male mice and $C d \times 2^{\text {loxP/loxP }}$ female mice.

\section{Antibodies and inhibitors}

Antibodies used for immunohistochemistry and Western blots include Cdx2 (Biogenex), Prkci (BD Transduction Laboratories), Par-3 (07-330, Millipore; 36-2301, Invitrogen), Prkcz (C-20, Santa Cruz Biotechnology), ZO-1 (Invitrogen), Laminin (abcam), Mark2 (Cell Signaling), Cdc42 (Cell Signaling), Par6A (G-9, Santa Cruz Biotechnology), Par6B (M-64, Santa Cruz Biotechnology), Lkb1 (Abcam), E-cadherin and Ctnnb1 (BD Transduction Laboratories), Tubulin (Sigma), Myo5b (Abcam), Myola (C-12, Santa Cruz Biotechnology), Myole (N-13, Santa Cruz Biotechnology), Myo6 (H-215, Santa Cruz Biotechnology), CaM (FL-149, Santa Cruz Biotechnology), Plastin (H-300, Santa Cruz Biotechnology), Spectrin (C-11, Santa Cruz Biotechnology), Ezrin (Cell Signaling), Rab8A (N-20, Santa Cruz Biotechnology), Rab27a (17817-1-AP, Proteintech Group), Rab1la (R0009, US Biological), EEA1 (Abcam), Lamp1 (Abcam, and 1D4B, Developmental Studies Hybridoma Bank), Lamp2 (Abcam), LC3A/B (Abcam), Catalase (Abcam), Cathepsin D (Abcam), $\mathrm{Na}^{+} / \mathrm{K}^{+}$-ATPase (a5, Developmental Studies Hybridoma Bank, The University of Iowa), and $\beta$-actin (Cell Signaling). For F-actin staining, fluorescent phallotoxins (Invitrogen) were used at a dilution of 1:40. Baf.A1, CHL, and leupeptin were purchased from Sigma.

\section{Caco-2 cells and 3D cyst formation}

Caco- 2 cells were grown in American Type Culture Collectionformulated Eagle's minimum essential medium containing $20 \%$ fetal bovine serum at $37^{\circ} \mathrm{C}$ in $5 \% \mathrm{CO}_{2}$. To form cysts, $1 \times 10^{4}$ cells in $1 \mathrm{~mL}$ of medium with $2 \%$ Matrigel (BD Transduction Laboratories) were plated in each well of the four-well chamber slides precoated with $150-\mu \mathrm{L}$ Matrigel. Medium was changed every $2 \mathrm{~d}$ for cysts to develop in periods of 1-9 d. To quantify lumen formation, cysts with a single central lumen were counted manually using an inverted microscope. More than 100 cysts from either control or knockdown cells were examined.

\section{Lentiviral shRNA-mediated CDX2 knockdown}

Caco- 2 cells at $50 \%$ confluency in $10-\mathrm{cm}$ dish were transduced by MISSION Lentiviral Transduction Particles against human CDX2 (Sigma, clone ID: TRCN0000013687), RAB27A (clone ID: TRCN000005296), RAB11A (Clone ID: TRCN0000073022), 
KIF3B (clone ID: TRCN0000116457) or Non-Target ShRNA Control Transduction Particles (Sigma, SHC002V), at 1-5 multiplicity of infection with $8 \mu \mathrm{g} / \mathrm{mL}$ Polybrene. After overnight transduction, viral particle-containing medium was replaced with fresh medium. Selection medium with $10 \mu \mathrm{g} / \mathrm{mL}$ puromycin was used in subsequent culture and experiments. Efficient CDX2 knockdown was confirmed by Western blot in cells within three passages. Only early-passage cells were used for cyst formation experiments.

\section{Confocoal immunofluorescence}

The confocoal immunofluorescent procedure for mouse tissue sections has been described in detail previously (Gao et al. 2009). Fluorescent staining for 3D Caco-2 cysts was performed as described previously for MCF-10A cells (Debnath et al. 2003). Movies were produced from Z-stack images using the Zeiss LSM Image Browser (version 4.0.0.241).

\section{EM analysis}

Samples for SEM were fixed in $2.5 \%$ glutaraldehyde and $2.0 \%$ paraformaldehyde in $0.1 \mathrm{M}$ cacodylate buffer, $(\mathrm{pH} 7.4)$ overnight at $4^{\circ} \mathrm{C}$. After several buffer washes, the samples were post-fixed in $2.0 \%$ osmium tetroxide for $1 \mathrm{~h}$, washed again in buffer, and dehydrated in a graded ethanol series. Samples were treated with several changes of hexamethyldisilazane (HMDS) and then allowed to air dry prior to mounting and sputter-coating with gold. SEM examinations were made, and images were taken in a Philips XL20 SEM. TEM has been described in detail previously (Gao et al. 2009).

\section{Western blot analysis}

Fresh tissue lysates from total small intestines or separated epithelia were prepared in lysis buffer containing $50 \mathrm{mM}$ Tris $(\mathrm{pH} 7.5), 150 \mathrm{mM} \mathrm{NaCl}, 10 \mathrm{mM}$ EDTA, $0.02 \% \mathrm{NaN}_{3}, 50 \mathrm{mM}$ $\mathrm{NaF}, 1 \mathrm{mM} \mathrm{Na} \mathrm{VO}_{4}, 1 \% \mathrm{NP} 40,1 \mathrm{mM}$ PMSF, and protease inhibitors (Sigma), from E18.5 mouse intestines. Fifteen micrograms of total lysates was heated for $10 \mathrm{~min}$ at $70^{\circ} \mathrm{C}$ in $4 \times$ LDS buffer (Invitrogen) and loaded on $4 \%-12 \%$ SDS-PAGE (Invitrogen). Proteins were transferred to PVDF membranes (Invitrogen) and were detected by antibodies. The procedure of intestinal epithelial separation has been described (Madison et al. 2009).

\section{CDC42 activation assay}

Embryonic intestinal tissues or Caco2 cells were quickly and thoroughly sonicated on ice. Seven-hundred microliters of tissue or cell lysates containing $1 \mathrm{mg}$ of total protein was mixed with $20 \mu \mathrm{g}$ of GST-Pak1-PBD (Thermo Scientific) and $50 \mu \mathrm{L}$ of glutathione resin. The reaction mixtures were rotated for $1 \mathrm{~h}$ at $4^{\circ} \mathrm{C}$. The resins were washed three times with lysis/binding/wash buffer $\left(25 \mathrm{mM}\right.$ Tris- $\mathrm{HCl}$ at $\mathrm{pH} 7.5,150 \mathrm{mM} \mathrm{NaCl}, 5 \mathrm{mM} \mathrm{MgCl}_{2}$, $1 \% \mathrm{NP}-40$, and $5 \%$ glycerol), heated in $20 \mu \mathrm{L}$ of $4 \times \mathrm{LDS}$ (Invitrogen) for $10 \mathrm{~min}$ at $70^{\circ} \mathrm{C}$, and subjected to Western blot analysis using rabbit anti-CDC42 antibody (Cell Signaling).

\section{In vitro protein kinase $C$ assay}

Caco-2 cells were rapidly sonicated in $1 \mathrm{~mL}$ of lysis buffer, $50 \mathrm{mM}$ Tris- $\mathrm{HCl}$ (pH 7.4), $150 \mathrm{mM} \mathrm{NaCl}, 2 \mathrm{mM}$ PMSF, 0.5\% Triton X-100, and $5 \mathrm{mM}$ EDTA, plus protease inhibitor and phosphatase inhibitor (Sigma). One milligram of lysates was incubated with $10 \mu \mathrm{g}$ of anti-Prkcz antibody (C-20, Santa Cruz Biotechnology) overnight at $4{ }^{\circ} \mathrm{C}$ with rotation. Immunoprecip- itates were collected by $30 \mu \mathrm{L}$ of protein G Sepharose beads after $1 \mathrm{~h}$ of incubation. Beads were washed once in lysis buffer, three times in lysis buffer without EDTA, and once in kinase buffer (20 mM Tris- $\mathrm{HCl}$ at $\mathrm{pH} 7.4,50 \mathrm{mM} \mathrm{NaCl}, 1 \mathrm{mM}$ PMSF, plus protease inhibitor, phosphatase inhibitor). For kinase assay, beads were resuspended in $25 \mu \mathrm{L}$ of kinase buffer plus $5 \mu \mathrm{g}$ of phosphatidylserine (Sigma), $2 \mu \mathrm{g}$ of myelin basic protein (Sigma), and $10 \mu \mathrm{Ci}$ of $\left[\gamma^{3}{ }^{32} \mathrm{P}\right]$ ATP (EHRS, University of Pennsylvania). For positive control, $0-1 \mu \mathrm{g}$ of purified GST-Pkczt fusion proteins (\#7608, Cell Signaling) was directly resuspended in a $30-\mu \mathrm{L}$ total kinase reaction mixture. Kinase reactions were performed for $10 \mathrm{~min}$ at $37^{\circ} \mathrm{C}$, and were stopped by adding $10 \mu \mathrm{L}$ of $4 \times$ LDS. Samples were denatured at $70^{\circ} \mathrm{C}$, and separated by SDS-PAGE. Proteins were transferred to PVDF membrane for autoradiograph.

\section{Microarray analysis}

One-centimeter small intestinal tissues of matched positions were dissected out from four pairs of E18.5 mutant and control embryos. Two-hundred-fifty nanograms of total RNA was amplified and labeled with Cy3 using the Low Linear Amplification Kit (Agilent Technologies). The details of microarray hybridization and data analysis have been described previously (Gao et al. 2009). Microarray data have been deposited into ArrayExpress under accession number E-MTAB-218.

\section{Gene functional annotation}

Gene functional classification was performed on differentially expressed genes with fold change $>1.5$-fold and false discovery rate $<10 \%$ between control and Cdx2-deficient small intestines. The Refseq_mRNA IDs of these genes were used for analysis by DAVID Bioinformatics Resources, NIH (Dennis et al. 2003). The classification stringency was set as "high" in all the analysis.

\section{Morphometric and densitomitry quantifications}

All quantifications of images and Western results were performed using Image J (version 1.38, NIH). Student $t$-test was used for the statistical analysis. Standard error of the mean was used for error bars in all the bar graphs.

\section{Acknowledgments}

We thank Karrie Brondell for the care of the animals; Dr. Jonathan Schug, Alan Fox, and Olga Smirnova for microarray analysis; Weier Li for excellent experimental assistance; and the Morphology Core of the Penn Center for the Study of Digestive and Liver Disease (P30DK50306), as well as the Functional Genomics Core of the Penn Diabetes Center (P30DK19525), for technical support. This work was funded in part by NIDDK grant DK053839 to K.H.K. N.G is supported by NIDDK K01 (1K01DK085194-01).

\section{References}

Ameen N, Apodaca G. 2007. Defective CFTR apical endocytosis and enterocyte brush border in myosin VI-deficient mice. Traffic 8: 998-1006.

Baricault L, Garcia M, Cibert C, Sapin C, Geraud G, Codogno P, Trugnan G. 1993. Forskolin blocks the apical expression of dipeptidyl peptidase IV in Caco-2 cells and induces its retention in lamp-1-containing vesicles. Exp Cell Res 209: $277-287$.

Barth AI, Caro-Gonzalez HY, Nelson WJ. 2008. Role of adenomatous polyposis coli (APC) and microtubules in directional 
cell migration and neuronal polarization. Semin Cell Dev Biol 19: 245-251.

Cramm-Behrens CI, Dienst M, Jacob R. 2008. Apical cargo traverses endosomal compartments on the passage to the cell surface. Traffic 9: 2206-2220.

Debnath J, Muthuswamy SK, Brugge JS. 2003. Morphogenesis and oncogenesis of MCF-10A mammary epithelial acini grown in three-dimensional basement membrane cultures. Methods 30: 256-268.

Dennis G Jr, Sherman BT, Hosack DA, Yang J, Gao W, Lane HC, Lempicki RA. 2003. DAVID: Database for annotation, visualization, and integrated discovery. Genome Biol 4: 3. doi: 10.1186/gb-2003-4-5-p3.

Etienne-Manneville S, Manneville JB, Nicholls S, Ferenczi MA, Hall A. 2005. Cdc42 and Par6-PKCל regulate the spatially localized association of Dlg1 and APC to control cell polarization. J Cell Biol 170: 895-901.

Gao N, White P, Kaestner KH. 2009. Establishment of intestinal identity and epithelial-mesenchymal signaling by $\mathrm{Cdx} 2 . \mathrm{DeV}$ Cell 16: 588-599.

Goldstein B, Macara IG. 2007. The PAR proteins: Fundamental players in animal cell polarization. Dev Cell 13: 609-622.

Groden J, Thliveris A, Samowitz W, Carlson M, Gelbert L, Albertsen H, Joslyn G, Stevens J, Spirio L, Robertson M, et al. 1991. Identification and characterization of the familial adenomatous polyposis coli gene. Cell 66: 589-600.

Hemminki A, Markie D, Tomlinson I, Avizienyte E, Roth S, Loukola A, Bignell G, Warren W, Aminoff M, Hoglund P, et al. 1998. A serine/threonine kinase gene defective in Peutz-Jeghers syndrome. Nature 391: 184-187.

Izumi T. 2007. Physiological roles of Rab27 effectors in regulated exocytosis. Endocr J 54: 649-657.

Jaffe AB, Kaji N, Durgan J, Hall A. 2008. Cdc42 controls spindle orientation to position the apical surface during epithelial morphogenesis. J Cell Biol 183: 625-633.

Jedrusik A, Parfitt DE, Guo G, Skamagki M, Grabarek JB, Johnson MH, Robson P, Zernicka-Goetz M. 2008. Role of $\mathrm{Cdx} 2$ and cell polarity in cell allocation and specification of trophectoderm and inner cell mass in the mouse embryo. Genes Dev 22: 2692-2706.

Joberty G, Petersen C, Gao L, Macara IG. 2000. The cell-polarity protein Par6 links Par3 and atypical protein kinase $\mathrm{C}$ to Cdc42. Nat Cell Biol 2: 531-539.

Lake BD. 1988. Microvillus inclusion disease: Specific diagnostic features shown by alkaline phosphatase histochemistry. J Clin Pathol 41: 880-882.

Lin D, Edwards AS, Fawcett JP, Mbamalu G, Scott JD, Pawson T. 2000. A mammalian PAR-3-PAR-6 complex implicated in Cdc42/Rac1 and aPKC signalling and cell polarity. Nat Cell Biol 2: $540-547$.

Madison BB, Dunbar L, Qiao XT, Braunstein K, Braunstein E, Gumucio DL. 2002. Cis elements of the villin gene control expression in restricted domains of the vertical (crypt) and horizontal (duodenum, cecum) axes of the intestine. I Biol Chem 277: 33275-33283.

Madison BB, McKenna LB, Dolson D, Epstein DJ, Kaestner KH. 2009. FOXF1 and FOXL1 link hedgehog signaling and the control of epithelial proliferation in the developing stomach and intestine. J Biol Chem 284: 5936-5944.

Marsh DJ, Kum JB, Lunetta KL, Bennett MJ, Gorlin RJ, Ahmed SF, Bodurtha J, Crowe C, Curtis MA, Dasouki M, et al. 1999. PTEN mutation spectrum and genotype-phenotype correlations in Bannayan-Riley-Ruvalcaba syndrome suggest a single entity with Cowden syndrome. Hum Mol Genet 8: 1461-1472.

Marsh V, Winton DJ, Williams GT, Dubois N, Trumpp A, Sansom OJ, Clarke AR. 2008. Epithelial Pten is dispensable for intestinal homeostasis but suppresses adenoma development and progression after Apc mutation. Nat Genet 40: 1436-1444.

Martin-Belmonte F, Gassama A, Datta A, Yu W, Rescher U, Gerke V, Mostov K. 2007. PTEN-mediated apical segregation of phosphoinositides controls epithelial morphogenesis through Cdc42. Cell 128: 383-397.

Matter K, Stieger B, Klumperman J, Ginsel L, Hauri HP. 1990. Endocytosis, recycling, and lysosomal delivery of brush border hydrolases in cultured human intestinal epithelial cells (Caco-2). J Biol Chem 265: 3503-3512.

Millman EE, Zhang H, Godines V, Bean AJ, Knoll BJ, Moore RH. 2008. Rapid recycling of $\beta$-adrenergic receptors is dependent on the actin cytoskeleton and myosin Vb. Traffic 9: 1958-1971.

Mirouse V, Swick LL, Kazgan N, St Johnston D, Brenman JE. 2007. LKB1 and AMPK maintain epithelial cell polarity under energetic stress. J Cell Biol 177: 387-392.

Morroni M, Cangiotti AM, Guarino A, Cinti S. 2006. Unusual ultrastructural features in microvillous inclusion disease: A report of two cases. Virchows Arch 448: 805-810.

Nabi IR, Dennis JW. 1998. The extent of polylactosamine glycosylation of MDCK LAMP-2 is determined by its Golgi residence time. Glycobiology 8: 947-953.

Qiu RG, Abo A, Steven Martin G. 2000. A human homolog of the C. elegans polarity determinant Par-6 links Rac and Cdc42 to PKC $\zeta$ signaling and cell transformation. Curr Biol 10: 697-707.

Saotome I, Curto M, McClatchey AI. 2004. Ezrin is essential for epithelial organization and villus morphogenesis in the developing intestine. Dev Cell 6: 855-864.

Sardiello M, Palmieri M, di Ronza A, Medina DL, Valenza M, Gennarino VA, Di Malta C, Donaudy F, Embrione V, Polishchuk RS, et al. 2009. A gene network regulating lysosomal biogenesis and function. Science 325: 473-477.

Sato T, Mushiake S, Kato Y, Sato K, Sato M, Takeda N, Ozono K, Miki K, Kubo Y, Tsuji A, et al. 2007. The Rab8 GTPase regulates apical protein localization in intestinal cells. $\mathrm{Na}$ ture 448: 366-369.

Schonteich E, Wilson GM, Burden J, Hopkins CR, Anderson K, Goldenring JR, Prekeris R. 2008. The Rip11/Rab11-FIP5 and kinesin II complex regulates endocytic protein recycling. J Cell Sci 121: 3824-3833.

Strumpf D, Mao CA, Yamanaka Y, Ralston A, Chawengsaksophak K, Beck F, Rossant J. 2005. Cdx2 is required for correct cell fate specification and differentiation of trophectoderm in the mouse blastocyst. Development 132: 2093-2102.

Tyska MJ, Mackey AT, Huang JD, Copeland NG, Jenkins NA, Mooseker MS. 2005. Myosin-1a is critical for normal brush border structure and composition. Mol Biol Cell 16: 2443-2457.

Weisz OA, Rodriguez-Boulan E. 2009. Apical trafficking in epithelial cells: Signals, clusters and motors. J Cell Sci 122: 4253-4266.

Yeaman C, Grindstaff KK, Hansen MD, Nelson WJ. 1999a. Cell polarity: Versatile scaffolds keep things in place. Curr Biol 9: R515-R517. doi: 10.1016/S0960-9822(99)80324-8.

Yeaman C, Grindstaff KK, Nelson WJ. 1999b. New perspectives on mechanisms involved in generating epithelial cell polarity. Physiol Rev 79: 73-98.

Yonemura S, Tsukita S. 1999. Direct involvement of ezrin/ radixin/moesin (ERM)-binding membrane proteins in the organization of microvilli in collaboration with activated ERM proteins. J Cell Biol 145: 1497-1509.

Zhang Y, Wick DA, Haas AL, Seetharam B, Dahms NM. 1995. Regulation of lysosomal and ubiquitin degradative pathways in differentiating human intestinal Caco-2 cells. Biochim Biophys Acta 1267: 15-24. 


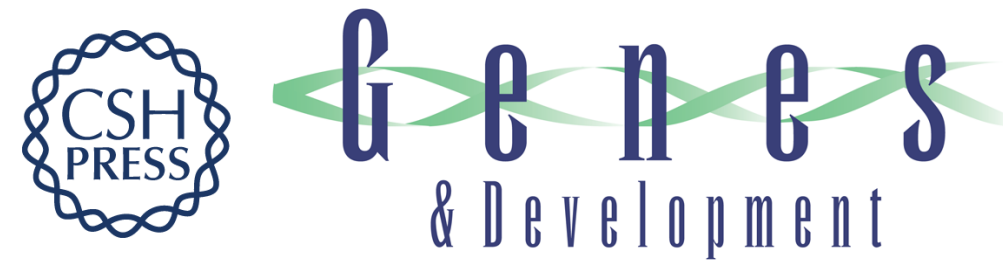

\section{Cdx2 regulates endo-lysosomal function and epithelial cell polarity}

Nan Gao and Klaus H. Kaestner

Genes Dev. 2010, 24:

Access the most recent version at doi:10.1101/gad.1921510

Supplemental

http://genesdev.cshlp.org/content/suppl/2010/06/09/24.12.1295.DC1

Material

References This article cites 39 articles, 14 of which can be accessed free at:

http://genesdev.cshlp.org/content/24/12/1295.full.html\#ref-list-1

License

Email Alerting Receive free email alerts when new articles cite this article - sign up in the box at the top Service right corner of the article or click here.

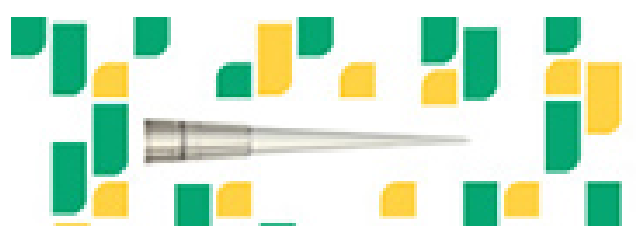

Focused on your science. 